Article

\title{
Towards (Hyper)Local Public Sphere: Comparison of Civic Engagement across the Global North
}

\author{
Jaana Hujanen ${ }^{1, *}$, Olga Dovbysh ${ }^{2}$, Lottie Jangdal ${ }^{3}$ and Katja Lehtisaari ${ }^{4}$ \\ ${ }^{1}$ Swedish School of Social Science, University of Helsinki, Finland; E-Mail: jaana.hujanen@helsinki.fi \\ ${ }^{2}$ Aleksanteri Institute, University of Helsinki, Finland; E-Mail: olga.dovbysh@helsinki.fi \\ ${ }^{3}$ Department of Media and Communication Science, Mid Sweden University, Sweden; E-Mail: lottie.jangdal@miun.se \\ ${ }^{4}$ Faculty of Information Technology and Communication Sciences, Tampere University, Finland; \\ E-Mail: katja.lehtisaari@tuni.fi \\ * Corresponding author
}

Submitted: 15 December 2020 | Accepted: 2 May 2021 | Published: 23 July 2021

\begin{abstract}
The role of hyperlocal media is of increasing relevance as traditional local journalism experiences a decline due to centralisation and consolidation. The affordances of Internet and digital technologies also enable hyperlocal initiatives to enhance civic engagement in localities and serve as a place and resource for local deliberative processes. This study examines how the aims, perceptions and practices of hyperlocal media vary in three countries of the Global North-Sweden, Finland and Russia-and what implications this has for connectedness and civic engagement in local public spheres. The context of different media systems and local political regimes help to explore possibilities and limitations of hyperlocals as agents of place-oriented civic engagement. The data includes interviews with practitioners and analysis of selected hyperlocal media. Our results indicate that hyperlocal media practitioners in all three countries aim to provide local people and communities with a voice, and to enhance resident engagement in local life. We reveal three civic roles of hyperlocal media: (i) information provider, (ii) community builder, and (iii) civic mediator. Practices of civic engagement used by hyperlocal media range from relying on civic journalism to fostering civic debates and can be classified in two main categories: civic information and civic debate and interaction. The perceptions and practices of these hyperlocal media are, to some extent, similar because of comparable changes and challenges regarding the local media and public spheres. At the same time, the perceptions of civic roles vary, reflecting both the developments and differences in the countries' media spheres and political regimes. This research raises a critical question about hyperlocal practitioners' understanding of their own roles and aims, and in addition, how differences in media cultures and local regimes affect their performance as agents of local public spheres.
\end{abstract}

\section{Keywords}

civic engagement; Finland; Global North; hyperlocal media; local media; public sphere; Russia; Sweden

\section{Issue}

This article is part of the issue "Spaces, Places, and Geographies of Public Spheres" edited by Annie Waldherr (University of Vienna, Austria), Ulrike Klinger (European University Viadrina, Germany) and Barbara Pfetsch (Freie Universität Berlin, Germany / Weizenbaum-Institute for the Networked Society, Germany).

(C) 2021 by the authors; licensee Cogitatio (Lisbon, Portugal). This article is licensed under a Creative Commons Attribution 4.0 International License (CC BY).

\section{Introduction}

The role of hyperlocal media is of increasing relevance as traditional local journalism is in decline, experiencing processes of centralisation, consolidation and devalua- tion in the age of 'platformisation.' Despite liminal field positions in terms of capital and resources, small hyperlocal media demonstrate physical proximity with their audiences and tend to produce a sense of community togetherness (Örnebring et al., 2020). The capacities of 
Internet and digital technologies enable hyperlocal initiatives to enhance local deliberative processes and present a multitude of local voices in public interest matters (Freeman, 2020).

Being a comparatively new addition to the local media sphere, hyperlocal media cover a wide range of initiatives, usually defined as media that target a limited geographical area, have a community orientation, contain original news reporting, are indigenous to the web, fill perceived news gaps and stimulate civic engagement (Metzgar et al., 2011). Researchers stress their small scale, independence from established media houses and orientation towards sharing citizen-driven content at a grassroots level-which makes these media a means for people's individual expression and involvement in local life and debates (Radcliffe, 2012; Turner, 2015). Initiatives span from non-profit operations to commercial businesses, with various levels of professionalisation (Tenor, 2018). What is common among these diverse outlets is their spatialised orientation, which affects the practices and logic of these media and the practitioners standing behind them (Rodgers, 2018).

As such, hyperlocal media have the potential to revive the local public sphere by facilitating fora for localised debates and welcoming material from neighbouring people and organisations. At the same time, hyperlocal media tend to reconsider the composition of the local public sphere by redefining what local news is and what the public interest is (Harte et al., 2019). The forms of civic engagement vary in different political regimes (Hujanen et al., 2020), so it is unclear how hyperlocal media perform in different media systems and journalistic cultures.

Despite its potential, the role of hyperlocal media in local civic engagement is neither evident nor uniform. To gain novel insights into the possibilities of hyperlocal media as agents of place-oriented civic engagement, this article examines the aims, roles and practices of hyperlocal practitioners and initiatives in three countries of the Global North: Sweden, Finland and Russia. The two Nordic countries are democracies with traditionally strong local media and emerging hyperlocal media. In Russia, the situation for independent media is challenging. Hyperlocal media in this media system act not only as grassroots initiatives but also as an alternative to state-controlled and digitally underdeveloped local media (Dovbysh \& Mukhametov, 2020). At the same time, the three countries have common geographical features with long distances between settlements, low population density in rural and remote areas and harsh climate conditions, which influence the role local media play in local communication.

This study thus seeks to understand how hyperlocal media practitioners understand and tackle their roles across the needs and potentials of local publics. We study both the similarities and differences that exist despite, or because of, inherent differences in media systems and local political regimes in these three countries of the Global North. To gain context-sensitive and nuanced insights into the aims, roles and practices of hyperlocal civic engagement in local public spheres in different media cultures and political regimes, this article seeks to answers the following questions: (i) How do hyperlocal practitioners perceive the civic role of their media in local public spheres in Sweden, Finland and Russia? (ii) What types of practices have hyperlocal media operations implemented to enhance civic engagement within their local contexts?

\section{Theoretical Framework}

\subsection{Local Public Spheres and the Role of Local Media}

The notion of the public sphere is changing in the digital era. The concept of the public sphere has usually been understood as a constellation of communicative spaces, where information, ideas and debates can circulate to form a political will, which is also called public opinion (Dahlgren, 2005). Dahlgren conceptualises the public sphere as consisting of three constitutive dimensions: structures, representation and interaction. The structural dimension refers to the institutional features of the media outlets, including their organisational form and ownership structure, sources of financing and legal framework. The representational dimension concerns the output of the media, its fairness, accuracy, pluralism of view, agenda setting and so forth. The interaction dimension constitutes the public space as a communicative relationship between speakers and hearers (Friedland et al., 2007, emphasis is original). As such, digital technologies and the Internet affect all three dimensions. Being indigenous to the web, hyperlocal media affect all three dimensions and therefore the constitution of the local(ised) public sphere. Below, we provide a brief overview of the role of digital local media for the public sphere.

First, the very notion of locality is changing in the digital world. In the boundless digital space, local media are no longer defined only by an attachment to a particular geographical place. Place is acquiring a more social meaning (Usher, 2019). Recent research suggests a 'geo-social' concept to highlight how local news media offer people a sense of place (Hess \& Waller, 2014). This is in line with Rodgers (2018, p. 856), who proposes that:

Practices of so-called hyperlocal media should be understood via a phenomenological duality. On the one hand, as activities rooted in place: conducting media work though situated environments. Yet, on the other hand, as inhabitations of field spaces: geographically dispersed social and technical worlds.

Further, Hess and Gutsche (2018) particularise the social and cultural forms of media and suggest the relevance of a social sphere when studying the functions of journalism. Despite the obvious importance of 'where,' it is one 
of the least investigated areas of the journalistic professional domain, and the links between place, local knowledge and the role of hyperlocals in the public sphere remain largely unexplored.

A long tradition of research has demonstrated the strong connection between local journalism and local community in both metropolitan and rural areas (Nielsen, 2015). Local news can foster community engagement and audience participation, providing communities with more agency in democratic processes (Nelson \& Kim, 2020; Wenzel, 2019). For instance, cities in the US have experienced significant drops in civic engagement after the closure of local newspapers (Shaker, 2014). This shows that local journalism is important for local political knowledge and for the community. What might not be important for people as individuals is important for the local society in which they live (Olsen, 2020). Residents expect local journalism providers to be 'good neighbours,' to care about the area and to provide a community forum rather than to fulfil watchdog functions and focus on rapid news reporting. People also wish for local media to prioritise solutions as much as problems (Heider et al., 2005).

Hyperlocal media are less visible so far in terms of their role in the public sphere. However, hyperlocal news sites engage the public in a different way compared to professional journalists and news organisations (Firmstone \& Coleman, 2015) and strive to establish a close and reciprocal relationship with their audience and to offer key values for citizens, including a route for participating in the public sphere (Harte et al., 2019). Hyperlocal media typically have an insider perspective to local life, and people contribute more to local groups, which offer a space for discussion, than to legacy media (Nygren \& Leckner, 2016). In this research, we consider the impact of hyperlocal media on the structural, representational and interactional dimensions of the public sphere to understand their place in the local(ised) public sphere in three countries.

\subsection{The Civic Role of Hyperlocal Media Practitioners}

How hyperlocal media practitioners perceive their roles is important for understanding the potential impact of hyperlocal media in the local public sphere. Practitioners typically express motives other than economic for starting a hyperlocal media operation (Leckner et al., 2017). For instance, in the UK, most hyperlocal producers identify their work as a form of active civic participation. 'Filling the news gap' is a common goal but articulated as a civic duty rather than a gap in the market (Radcliffe, 2015).

At the same time, the civic potential of hyperlocal media should not be considered as a one-dimensional benevolent process. It is not always the aim of the initiatives to enhance civic engagement, as the goal of the hyperlocal practitioner can be to stimulate local businesses, engage in local activism or politics. Civic engage- ment may not always be for the greater good or democratically desirable. Citizen participation in the newsmaking process became a hopeful promise in the 1990s, but since then a bleak flip side to these utopian ideas has surfaced-a concept which Quandt calls 'dark participation' (2018). Quandt cautions against equating 'civic engagement' with 'normative good.' For that reason, it is important not to confuse so-called 'alternative media' and partisan interest communication with communityoriented hyperlocals with a multi-dimensional content and news focus.

Over the course of decades, some of the prominent roles identified among professional journalists are the roles of disseminator, interpreter, adversary, populist mobiliser and civic. Lately, a decline in the disseminator role and an increase in the interpretive role have been noted (e.g., Willnat et al., 2019). Variations in the prominence of certain roles and the emergence of new ones, such as that of the populist mobiliser, reflect the changing journalism terrain over time, such as the increase of citizen engagement. Chung and Nah (2013) found that citizen journalists in the US tended to see their own role as that of populist mobilisers, while viewing professional journalists in the roles of interpretation and dissemination. According to Chadha (2016, pp. 704-706), who has examined how hyperlocal practitioners negotiate their work identities, the role of hyperlocal practitioners closely connects in their identity negotiation to the community and neighbourhood-reporting "on the side of the community," serving the neighbourhood or being "community campaigners."

We do not analyse practitioners' role perceptions against the aspects of the profit and professionalism of the initiatives (see e.g., Tenor, 2018), or from the viewpoint of individuals' renegotiation of their work identity (see e.g., Chadha, 2016). Our goal is to understand, first, how hyperlocal practitioners perceive their civic role in/for the community-that is, what kind of roles they want their media initiatives to have in the local public sphere. Second, our aim is to understand how practitioners' perceptions of the roles of hyperlocal sites are locally embedded constructions - that is, created and made sense of against the needs and potentials of media and political spheres. In other words, we are interested in what kinds of differences exist between the role perceptions of practitioners operating in different cultural, journalistic and political contexts and how it affects the hyperlocal media they develop.

\section{The Study in Context}

Finland and Sweden are characterised by universal media and communications services, strong and institutionalised media freedom - a model called the Nordic media welfare state (Syvertsen et al., 2014). In the Finnish media culture, despite digitalisation, local printed media still have a rather strong position compared to many other countries. The majority 
of newspapers there are small, local, and politically independent dailies. Most local newspapers belong to larger media companies (Grönlund \& Björkroth, 2011). Local media vary from professional news producers to hybrid forms of marketing and local information sharing (Hujanen et al., 2019). In Sweden, professional news media hold a relatively resilient position, with a stable public service media and a daily press with wide distribution and editorial presence (Weibull et al., 2018). However, since 2004, as part of a process of centralisation and consolidation, nearly half of the editorial offices of local newspapers have been shut down (Leckner et al., 2017). The weakening position of traditional local media and journalism, the emergence of hyperlocal initiatives as well as the eroding social cohesion at the local level, make both Finland and Sweden fruitful Nordic contexts to study hyperlocal practitioners' perceptions of the civic role of their media in the local public spheres.

The Russian media system is characterised as a dualistic one. There are elements like commercial advertising, news journalism, and private media capital which were adopted from Western models after the collapse of the Soviet Union. Close relations with political power, the impossibility of private ownership in certain media, and the comparatively low participation of citizens in the public sphere are indigenous to the Russian media system (Kiriya, 2018).

Russian local media have typically been highly dependent on financial support from local authorities (Dovbysh \& Mukhametov, 2020). Clientelistic relationships with the authorities, coupled with self-censorship, have contributed both to the crisis of journalistic values and professional authority (Roudakova, 2017) as well as to people's decreasing trust in local media ("TV, Internet," 2016). These tendencies have alienated the local professional media from their communities and increased "the distance between power-and media allied with that power-from local problems" (Kiriya, 2020, p. 174). The increasing popularity of digital, non-professional media-mainly on social media platforms - is a logical response to the call for relevant and independent local information and a space for local communication in Russian provinces.

This research is designed as a comparative study. Comparative studies are crucial for understanding communication in fragmented public spheres, weak legacy media systems and disrupted democracies (Bennett \& Pfetsch, 2018, p. 250). The most common type of comparative journalism research is cross-national research on media models, whereas comparative analysis of journalism at the level of media outlets has received less attention (Örnebring, 2012). As a base for this comparative study lies three parallel studies, independent of each other but within geographical proximity, which provides a unique opportunity to compare field data and broaden the scope of hyperlocal media as agents of the local public sphere. The selection of the three countries studied was motivated mainly by the authors' access to the empirical data in these countries. At the same time, the authors' previous research (Dovbysh \& Mukhametov, 2020; Jangdal et al., 2019) demonstrates that the local media in these three countries have both differences and similarities which justify a comparative analysis.

\subsection{Interview Data Gathered}

Our data combines qualitative interviews with hyperlocal media producers as well as analysis of selected initiatives. The main data consist of 53 semi-structured qualitative interviews conducted in 2017-2019: 23 in Sweden, 12 in Finland and 18 in Russia. 14 of the interviewees were female and 39 were male. The group of interviewees represents a somewhat diverse group of actors in terms of their professional background and current activities. Some respondents have professional experience in legacy media, while others have never worked as professional journalists. Some pursue commercial goals, while the majority has non-commercial motives. All hyperlocal media the interviewees represent are independent from established media outlets. The platforms where they run their media vary. In Russia, hyperlocal media are run mainly on social media platforms, while in Sweden and Finland they have their own websites. The localities of the media outlets studied range from small rural settlements to urban areas. To gain a better understanding of the context and practices mentioned by the respondents in the interviews, we observed all hyperlocal websites run by the informants, focusing on what forms of civic engagement was offered. The interviews were recorded, transcribed and analysed qualitatively, marking important statements and quotations under chosen themes and roles. Although there are differences regarding the size and content of the interview data per country, the data are still rich and comparable enough to illustrate key similarities and differences in practitioners' perceptions.

\section{Results}

\subsection{Hyperlocal Practitioners' Perceptions of Their Civic Role}

Below, we focus on how the practitioners make sense of and describe their civic role, as well as how their perceptions affect the dynamics of local media and transformations of the localised public sphere. Fostering civic engagement and strengthening the local public sphere are represented as central but with multifaceted aims of hyperlocal media practitioners throughout the Global North. However, civic goals do not apply in a similar way to all hyperlocal media studied. Within our data, three civic roles are constructed for the hyperlocal media: (i) information provider, (ii) community builder, and (iii) civic mediator. These analytical roles are not mutually exclusive, however.

First, within the civic role of a local information provider, the task of informing and filling the local news 
gap is central. Hyperlocal practitioners wish to inform residents about what is happening in the community from a grassroots perspective, with a focus on topics that are not covered by other media and with a sense of "I was there.' In some initiatives, the aim is to provide people with news in one's own language. As the resources of the operations vary, there are obvious differences in how operators are in practice able to fulfil their role as information providers.

Regarding news making and information sharing, practitioners share an aim of providing accurate, truthful, and trustworthy representations of local issues and events, without sensationalism or a strong emphasis on negative news. As put by an interviewee from Russia: "I do not want to demonstrate an image of a well-being town; I want to demonstrate that the town is not that bad and that we should notice not only negative, but also positive things."

In addition, sharing local news and information is represented as a question of local democracy. The practitioners aim at providing local information at an early stage in order for people to have an opportunity to react, speak, and make their voices heard. As perceived by the interviewees, if people do not have adequate information about what is happening in their communities, there will be decisions people were never made aware of and they stop caring: "When you don't know and understand the process you stop caring. You cannot protest and criticise propositions if you are not aware of them" (Sweden).

The motivation for the role of information provider differs between Finland and Sweden on the one hand, and Russia on the other. This indicates that the justifications are contextually constructed and reflect diversities in the structures and developments of the media and political sphere. In Finland and Sweden, justification for informing people about local and positive issues comes typically from the fact that professional news media focus on negative news. Moreover, professional journalists have left several rural municipalities in the Global North, leading to news deserts and information deficits. As noted by interviewees, many local issues would never make it into the mediated agenda without them and residents who take action.

While Nordic hyperlocal practitioners regard their media as a counterforce to non-existing or negativeslanted professional news media, hyperlocal media is perceived among Russian colleagues as a counterweight to biased and non-independent local professional media. Filling the news gap is represented as being a function of the poor quality of professional media, where 'quality' is a political issue and a question of journalistic autonomy and freedom. While professional local media is financed by the local government in Russia, hyperlocal operations are independent. Following this, practitioners see themselves as free, independent, and truth-seeking actors.

To some extent, the perception of own agency in local politics applies to practitioners across the Global North. Compared to professional journalists, hyperlocal practitioners see themselves as having a more free and independent position in the media ecosystem. This is viewed as a very important value. As stated by a Swedish interviewee: "When you interview a politician, you must be aware of the agenda that the politician has, or you end up becoming a spokesperson for what that political party wants on the table." The Russian practitioners distinguish between 'political' and 'non-political' issues and see their civic role as being that of a non-political social helper. They avoid discussing pure 'political' issues and challenging the existing political order or vertical power structure. Instead, they focus on the 'non-political social sphere' to help people with particular problems.

Within the role of community builder, the aims for strengthening and mirroring local community and identity, as well as activating people, are represented as central. This aim is connected to globalisation and individualisation. As a counterweight, a civic goal is constructed to help practitioners themselves and other people living in the same city or street corner to be 'locally present,' rooted, and integrated. For example, a Finnish founder of a hyperlocal initiative had felt himself as 'an outsider' in his own neighbourhood. Within the role of community builder, it is important to enhance a sense of community both virtually and physically in real life-so that people get to know each other and become part of the community. This is why practitioners wish to organise actions and events for local people.

In the Russian context, the civic role of a community builder is represented as having the aim of making people's identity stronger as local citizens: "We are trying to increase civic consciousness. The aim is also to force local officers 'to do good things.' " The role of community builder is represented as a service to other people and as a personal social project: "I had a very gratifying feeling that I was able to influence something, that my resource had significance. This is a social project for me" (Russia).

The civic role of a mediator includes the goal of facilitating interactions, local debate, and civic journalism. Practitioners aim at offering people and civic groups an opportunity, platform, and resources to meet, discuss, and give their voices to public debate and participate in local society. The vivid public dialogue is seen as important for democracy and the local public sphere: "The public dialogue is vital. It is absolutely necessary for the democratic conversion to function. My view of society rests on the fact that there is a continuing dialogue. This is the foundation of journalism and for civil society" (Sweden).

The role of civic mediator is about establishing good collaborative practices for people and civic groups, in order for local democracy to work. It is important to facilitate making news together, in particular by enhancing citizen journalism and people's chances to contribute and comment on the news agenda. Practitioners strongly value the fact that different types of people are involved and that different viewpoints are included and published. As stated by a Russian interviewee: "If anyone 
is interested in voicing his or her opinion about what is going on in the town-this is the place where you can do it."

\subsection{Practices for Enhancing Civic Engagement}

Next, we analyse which practices hyperlocal operations have implemented in order to enhance civic engagement within their local context. In terms of their practice, we refer to the ways the hyperlocal operators act in order to get people engaged. Thus, we ask what concrete actions the publications perform locally. The analysis is based on the interview data and digital observations.

Hyperlocal practitioners in the countries studied share similar practices in order to serve the local community and act as the virtual place where locals can participate in civic activities, but the analysis also reveals differences. Two categories of practices can be distinguished: civic information and civic debate and interaction. The civic information practices are further divided into practices for individual persons and those for local organisations.

The civic information practices for individuals are about reader and/or citizen participation. They broaden the scope of participation and civic engagement by offering people the possibility to express themselves and share their thoughts publicly in a moderated environment. The actions include ways and tools that help local people to act as civic journalists and which support their involvement in content production. The practices applied vary from publishing stories that are fully generated by local residents to the opportunity for people to share information that is used by journalists for writing stories.

Content making, technical support, and mentoring, as well as networking-oriented practices, are forms of civic information practices for individuals. The first group includes columns for guest writers (Sweden and Finland) and citizen bloggers (Russia), as well as training for civic journalists (Sweden and Finland). In the light of the data, practitioners can take a mentoring role when inviting people to participate. They offer for example training and support for publishing user-generated material. The second group refers to launching technical solutions, such as payment to civic journalists according to traffic (Sweden) or making a section 'to offer the news' for one-click news submission (Russia). The group of networking practices includes coordinating former journalists to contribute regularly (Sweden), creating networks which provide contributors with particular knowledge within various aspects of local society to facilitate citizen contributors (all countries).

The civic information practices for organisations offer associations, non-governmental, municipal, or state organisations a place to publish and distribute information on actual issues and activities. The municipal or state actors may be, for example, local police, the fire department, or a museum. These practices mediate information without someone in between the organisation and the audience. The practices can also include entertaining elements.

In Sweden and Finland, the civic information practices for organisations seem to contribute to a sense of local togetherness and community building. For example, a hyperlocal media outlet in northern Sweden plays an important part in a yearly community celebration where new-borns are presented with gifts. In Finland, initiatives organise offline events for people to gather. Spreading information is an important aspect for the initiatives, as well as to enhance everyday interactions and communication between people.

The civic debate and interaction practices include activities to involve people in decision-making and discussions of local affairs as well as to foster direct communication between officials and people. Hyperlocal media invite people to discuss issues on their own sites or on social media platforms in the Nordic countries. These practices vary between hyperlocal media and the countries studied but are about providing a platform to comment and discuss current issues. In Sweden, it is typical for hyperlocal media to report on local government plans so that residents have an opportunity to react before decisions are made.

Even though it is important for the Nordic practitioners that different viewpoints meet in the local public sphere, the quality is seen to require moderation of the comments. As observed by a Swedish interviewee:

A commentary function is a way to listen to the entire population, and it adds to reader value. It's important, though, to have a responsible handling of comments. We don't have threaded comments for that reason. Certain words are also banned.

A difference compared with Russian initiatives is that as they consider themselves as independent from local authorities (in comparison to legacy media), hyperlocal media practitioners praise their weak moderation practice: "Everything is possible [to discuss] with us, just do not get personal."

In the light of the data gathered, we revealed a need among the people to have a hyperlocal platform for discussion. For example, an article about a local church building raised a vivid discussion in a small Finnish hyperlocal media and became one of the most debated stories in the history of this hyperlocal initiative: "As the church is an issue of utmost concern to the village, the issue is perceived as very close, as 'our own.' It is possible that everyone has something to say about this." In Russia, hyperlocal media serve to collect information for local governments about people's opinions on local development, like urban planning, housing, and communal services. To fulfil this aim, hyperlocal media publish surveys and questionnaires and report the results to the city administration.

Practices used by Russian hyperlocal initiatives are to a great extent determined by the unfree position 
of legacy local media and their dependence on state finance. Hyperlocal media aim to fulfil the normative functions of media and to bridge the gap in local civic engagement. Having a huge audience on a city scale, the hyperlocal media have power to challenge the local officials unlike professional and financially-dependent media: "When you have a couple of thousand signatures of actual people behind you, your request gets a response very quickly, even if it was sent from an individual" (Russia). Therefore, their practices often include writing petitions or requests to the local government. Our results also demonstrate that some hyperlocal media serve as a space for direct communication between authorities and citizens. A Russian initiative, for example, organises live streaming with the city mayor, who answers questions submitted by the hyperlocal audience on social media platforms.

\section{Conclusions}

The role of local news media in civic engagement is less studied than that of social networking, top-down platforms or websites intentionally created to enhance collaboration between citizens and public institutions (Bartoletti \& Faccioli, 2016; De Cindio \& Peraboni, 2011). To get more context-sensitive and nuanced insights, this article has examined how hyperlocal practitioners perceive the civic duty of their media in local public spheres of Sweden, Finland and Russia. The article also studies what types of practices hyperlocal media outlets have implemented to enhance civic engagement.

The aim of hyperlocal media to function as agents for the local public sphere-to engage with people being as important as producing news for and with themis present throughout the Global North. Fostering civic engagement and strengthening the local public sphere are represented as central but with multifaceted aims by practitioners. Similarities can be seen both in the perceptions of the practitioners as well as practices of hyperlocal operations in the countries studied. The three intertwining civic roles for hyperlocal media are understood by practitioners from the Global North as (i) information provider, (ii) community builder, and (iii) civic mediator. Within the first, sharing local news and information is represented as a key aspect of local democracy. Providing local information at an early stage and from a grassroots perspective is seen as important for people to have an opportunity to react, speak, and make their voices heard (see also Tenor, 2018). Within the second role, as a counter force for globalisation and individualisation, a civic goal is to help practitioners themselves and other people to be able to be locally present, rooted, and integrated in the community. The civic role of a mediator is about facilitating interactions, local debate, and civic journalism.

While the first role is one of those traditionally ascribed to professional journalists (e.g., Willnat et al., 2019), our study indicates that hyperlocal practitioners, like citizen journalists, consider newer roles, such as the populist mobiliser and civic roles, as important (e.g., Chung \& Nah, 2013). This study indicates that hyperlocal media practitioners from the Global North, who often lie between professional and amateur or 'pro-ams,' perceive their roles as closely attached to local communities and ordinary citizens. Many perceive it important for hyperlocal media to let people express views and to motivate people to get involved. Many also said they find it as important to report fairly and accurately but with the purpose of serving their community. Bringing our results together with observations from the US (Chadha, 2016), it can be concluded that, in the practitioners' sense-making, hyperlocal information providers or media are not only content creators, but also populist mobilisers, community builders and campaigners. It is thus important that the roles ascribed to hyperlocal media are constructed from the viewpoint of the community, being part of the community and reporting on the side of the community.

Two categories characterise the civic practices of the hyperlocal media studied: civic information and civic debate and interaction. Civic information practices for individuals include content making, technical support and mentoring, as well as networking-oriented practices. The practices for local organisations are about offering civic associations-non-governmental as well as municipal organisations - a place to publish their activities and distribute information on actual issues. These practices are important in bringing the possibility of mediating information directly between the organisations, authorities, and local people. It can also be claimed that via these kinds of practices, hyperlocal initiatives address media users' expectations of local journalism providers to care about the area, and to provide a community forum (Poindexter et al., 2006). The civic debate and interaction category includes activities to involve people in decision-making and discussions of local affairs as well as to foster communication between officials and local people.

As we see it, the perceptions and practices are to some extent similar in the three countries studied as the changes and challenges regarding the local media and public spheres are similar: the detachment of local government from the local community (Kiriya, 2018) and gaps in local reporting by professional news media (e.g., Leckner et al., 2017). At the same time, our analysis indicates that the perceptions for civic roles can and do vary, reflecting both the developments and differences in the countries' media sphere as well as configurations and power relations of the political regimes. Regarding role perceptions, the roles of information provider and civic mediator are central for Russian practitioners, who think that trustworthy local news and a forum for dialogue do not otherwise exist. The community builder role has a strong presence in the perceptions of Finnish and Swedish hyperlocal practitioners, while the democratic watchdog role seems not to be so central for them. 
Regarding practices, differences between the hyperlocal media in Finland and Sweden, on the one hand, and Russia, on the other, are also visible. Our study indicates that Russian hyperlocal grassroots media aim to bridge the gap in local civic engagement, offering a platform for open communication and letting people freely discuss issues. These practices among Russian hyperlocals reflect the characteristics of the local media model and political sphere-that is, dependence on state financing, unfree professional local media and weak communication between local authorities and people.

It is also noteworthy that while hyperlocal media share similar practices oriented towards civic engagement, the rationales behind similar practices may differ. In other words, even if hyperlocal media act in comparable ways, practitioners seem to make sense of them differently. Within our data, this becomes visible in, for example, the discursive construction of journalistic autonomy - that is, how the need for independence is represented and made sense of by the practitioners in different cultures in diverse ways. For the Finnish and Swedish practitioners studied, corporate independence and grassroots and insider perspectives to news reporting are important. At the same time, Russian hyperlocal media practitioners stress the significance of freedom of speech and their political independence. These differences can be at least partially understood against the processes and needs coming from the wider media spherethat is, from the fact that traditional local media in Russia is highly controlled (Dovbysh \& Mukhametov, 2020), while in Finland and Sweden, alongside with centralisation and market-orientation, there are fewer resources within traditional local news media to invest in covering local issues.

Via our comparative approach, we are able to conclude that journalists' and media practitioners' role conceptions should not be detached from their cultural contexts. Journalism and communication scholars should be careful not to propose that results from one specific context would apply to professional or citizen journalists or hyperlocal practitioners 'in general.' Instead, role perceptions, being discursive constructions, need to be studied as an inherently social phenomenon within their specific historical, cultural and interactional contexts. This finding can be applied to the further clarification and reconsideration of the definition and understanding of hyperlocal media. In comparison to earlier definitions (e.g., Metzgar et al., 2011), we suggest that instead of a definition based on a composite of generic characteristics of hyperlocal media, the focus should be on the roles, practices and values of hyperlocal media in the local community. The ascending logic, taking into account the practitioners' viewpoints and reflections (Rodgers, 2018), should be used, and the influence of broader cultural and socio-political contexts should be considered as well. Our research also suggests another perspective on the study of hyperlocal media and practitioners: Instead of studying them in contrast or in relation to professional media and journalists (Chadha, 2016; Tenor, 2018), we suggest examining them as a part (or extension) of the local community they serve. This perspective suggests the need to focus on their (civic) roles in and for the local community and public engagement.

Our more general aim in this research was to understand the possible implications of hyperlocal media for the local(ised) public sphere. Based on Dahlgren's (2005) conceptualisation of the public sphere as a constitution of three constitutive dimensions-structural, representational and interactional-we conclude by discussing how hyperlocal media may contribute to the transformation of all three dimensions in relation to local(ised) public spheres in three countries studied. Reconsideration of the structural dimensions refers to different (compared to established local media) institutional features of own performance. Praising their independence from bigger media corporations (Sweden and Finland) or from the government and other political forces (Russia), hyperlocal practitioners have a multitude of logics and motivations for their own activities in the society. Taking into account the non-commercial nature of many hyperlocals and the non-journalistic background of some practitioners, hyperlocal media have the potential to subvert the established logics and practices of local communication and debates. Moreover, hyperlocal media not only passively inform about local events but also have the agency to challenge local politics and criticise local politicians.

The representational dimension is determined by hyperlocal practitioners' understanding of the values and principles they rely on in their activities. They aim to offer values for citizens, such as a route to participate in the public sphere supporting everyday active citizenship and civic consciousness. Unlike professional journalists' ideals (Hujanen, 2016), the value of care is articulated as important. The task of hyperlocal practitioners is represented by some both as a service and as a help to other people, including important personal social projects. Objectivity thus becomes a contested notion (Harte et al., 2019, pp. 199-200): The lack of objectivity of grassroots media can result in greater civic value. Instead of regarding themselves as detached objective reporters, hyperlocal practitioners are committed to enhancing community cohesion.

The impact on the interactional dimension is determined by the reconsideration of the closeness to the place and the local proximity of hyperlocal media to the community they serve. Being part of the community, hyperlocal media tend not only to reconsider what local information is worth discussing but also to reassess who has access to and is visible in local debates. As such, local events, ranging from children's births and everyday routine events to church renovation and local elections, are intertwined into a mediated public sphere, (co)produced by local residents.

We are aware that these findings are not generalisable to the entire field of hyperlocals, even within the Global North. Each hyperlocal media outlet is unique 
and the output and aims very much reflect the views of the practitioner(s). Another limitation is that our study focuses on the practitioners' aspects. In the future, audience research would be desirable to gain a more nuanced picture of the links between hyperlocal media and the outcomes of civic engagement.

\section{Conflict of Interests}

The authors declare no conflict of interests.

\section{References}

Bartoletti, R., \& Faccioli, F. (2016). Public engagement, local policies, and citizens' participation: An Italian case study of civic collaboration. Social Media + Society, 2(3). https://doi.org/10.1177/205630511 6662187

Bennett, W. L., \& Pfetsch, B. (2018). Rethinking political communication in a time of disrupted public spheres. Journal of Communication, 68(2), 243-253. https:// doi.org/10.1093/joc/jqx017

Chadha, M. (2016). What I am versus what I do: Work and identity negotiation in hyperlocal news startups. Journalism Practice, 10(6), 697-714. https://doi.org/ 10.1080/17512786.2015.1046994

Chung, D. S., \& Nah, S. (2013). Media credibility and journalistic role conceptions: Views on citizen and professional journalists among citizen contributors. Journal of Mass Media Ethics, 28(4), 277-288. https:// doi.org/10.1080/08900523.2013.826987

Dahlgren, P. (2005). The Internet, public spheres, and political communication: Dispersion and deliberation. Political communication, 22(2), 147-162.

De Cindio, F., \& Peraboni, C. (2011). Building digital participation hives: Toward a local public sphere. In M. Foth, L. Forlano, C. Satchell, M. Gibbs, \& J. Donath (Eds.), From social butterfly to engaged citizen: Urban informatics, social media, ubiquitous computing, and mobile technology to support citizen engagement (pp. 93-114). MIT Press.

Dovbysh, O., \& Mukhametov, O. (2020). State information contracts: The economic leverage of regional media control in Russia. Demokratizatsiya: The Journal of Post-Soviet Democratization, 28(3), 367-391.

Firmstone, J., \& Coleman, S. (2015). Public engagement in local government: The voice and influence of citizens in online communicative spaces. Information, Communication \& Society, 18(6), 680-695. https:// doi.org/10.1080/1369118x.2014.98618

Freeman, J. (2020). Differentiating distance in local and hyperlocal news. Journalism, 21(4), 524-540. https:// doi.org/10.1177/1464884919886440

Friedland, L. A., Long, C. C., Shin, Y. J., \& Kim, N. (2007). The local public sphere as a networked space. In R. Butsch (Ed.), Media and public spheres (pp. 43-57). Palgrave Macmillan.

Grönlund, M., \& Björkroth, T. (2011). Newspaper mar- ket concentration, competitive pressure and financial performance: The case of Finland. Journal of Media Business Studies, 8(3), 19-50. https://doi.org/ 10.1080/16522354.2011.11073525

Harte, D., Howells, R., \& Williams, A. (2019). Hyperlocal journalism: The decline of local newspapers and the rise of online community news. Routledge.

Heider, D., McCombs, M., \& Poindexter, P. M. (2005). What the public expects of local news: Views on public and traditional journalism. Journalism \& Mass Communication Quarterly, 82(4), 952-967. https:// doi.org/10.1177/107769900508200412

Hess, K., \& Gutsche, R. E. (2018). Journalism and the "social sphere": Reclaiming a foundational concept for beyond politics and the public sphere. Journalism Studies, 19(4), 483-498. https://doi.org/ 10.1080/1461670X.2017.1389296

Hess, K., \& Waller, L. (2014). Geo-social journalism: Reorienting the study of small commercial newspapers in a digital environment. Journalism Practice, 8(2), 121-136. https://doi.org/10.1080/17512786. 2013.859825

Hujanen, J. (2016). Participation and the blurring values of journalism. Journalism Studies, 17(7), 871-880. https://doi.org/10.1080/1461670X.2016.1171164

Hujanen, J., Dovbysh, O., Tenor, C., Grönlund, M., Lehtisaari, K., \& Lindén, C.-G. (2020). At the crossroads of hobby, community work and media business: Nordic and Russian hyperlocal practitioners. In A. Gulyas \& D. Baines (Eds.), The Routledge companion to local media and journalism (pp. 267-275). Routledge.

Hujanen, J., Lehtisaari, K., Lindén, C.-G., \& Grönlund, M. (2019). Emerging forms of hyperlocal media: The case of Finland. Nordicom Review, 13(1), 68-89. https://doi.org/10.2478/nor-2019-00299

Jangdal, L., Cepaite Nilsson, A., \& Stúr, E. (2019). Hyperlocal journalism and PR: Diversity in roles and interactions. OBS: Observatorio, 13(1), 1-20. https://doi. org/10.15847/obsOBS13120191278

Kiriya, I. (2018). Russian media. In I. Studin (Ed.), Russia: Strategy, policy and administration (pp. 97-103). Palgrave Macmillan.

Kiriya, I. (2020). Central and local media in Russia: Between central control and local initiatives. In A. Gulyas \& D. Baines (Eds.), The Routledge companion to local media and journalism (pp. 167-175). Routledge.

Leckner, S., Tenor, C., \& Nygren, G. (2017). What about the hyperlocals? Journalism Practice, 13(1), 68-89. https://doi.org/10.1080/17512786.2017.1392254

Metzgar, E. T., Kurpius, D. D., \& Rowley, K. M. (2011). Defining hyperlocal media: Proposing a framework for discussion. New Media \& Society, 13(5), 772-787. https://doi.org/10.1177/1461444810385095

Nelson, J. L., \& Kim, S. J. (2020). Improve trust, increase loyalty? Analyzing the relationship between news credibility and consumption. Journalism Practice, 15(3), 348-365. https://doi.org/10.1080/17512786. 2020.1719874 
Nielsen, R. K. (2015). Local newspapers as keystone media: The Increased importance of diminished newspapers for local political information environments. In R. K. Nielsen (Ed.), Local journalism: The decline of newspapers and the rise of digital media (pp. 51-72). I. B. Tauris.

Nygren, G., \& Leckner, S. (2016). Facebook och hyperlokalt i de lokala mediernas ekosystem [Facebook and hyperlocals in the ecosystem of local media]. In J. Ohlsson, H. Oscarsson, \& M. Solevid (Eds.), Ekvilibrium [Equilibrium] (pp. 329-348). SOM-institutet.

Olsen, R. K. (2020). Understanding the relationship people in their early adulthood have to small-town news and paywalls. Journalism, 21(4), 507-523. https:// doi.org/10.1177/1464884919886438

Örnebring, H. (2012). Comparative journalism research: An overview. Sociology Compass, 6(10), 769-780. https://doi.org/10.1111/j.1751-9020.2012.00493

Örnebring, H., Kingsepp, E., \& Möller, C. (2020). Journalism in small towns. Journalism, 21(4), 447-452. https://doi.org/10.1177/1464884919886442

Poindexter, P. M., Heider, D., \& McCombs, M. (2006). Watchdog or good neighbor? The public's expectations of local news. Harvard International Journal of Press/Politics, 11(1), 77-88. https://doi.org/ 10.1177/1081180X05283795

Quandt, T. (2018). Dark participation. Media and Communication, 6(4), 36-48. https://doi.org/10.17645/ mac.v6i4.1519

Radcliffe, D. (2012). Here and now: UK hyperlocal media today. Nesta. https://media.nesta.org.uk/ documents/here_and_now_uk_hyperlocal_media_ today.pdf

Radcliffe, D. (2015). Where are we now? UK hyperlocal media and community journalism in 2015. SSRN. https://ssrn.com/abstract=3045571

Rodgers, S. (2018). Roots and fields: Excursions through place, space, and local in hyperlocal media. Media, Culture \& Society, 40(6), 856-874. https://doi.org/ $10.1177 / 0163443717729213$
Roudakova, N. (2017). Losing Pravda: Ethics and the press in post-truth Russia. Cambridge University Press.

Shaker, L. (2014). Dead newspapers and citizens' civic engagement. Political Communication, 31(1), 131-148. https://doi.org/10.1080/10584609.2012. 762817

Syvertsen, T., Enli, G., Mjøs, O. J., \& Moe, H. (2014). The media welfare state. University of Michigan Press.

Tenor, C. (2018). Hyperlocal news and media accountability. Digital Journalism, 6(8), 1064-1077. https:// doi.org/10.1080/21670811.2018.1503059

Turner, J. (2015). Good dog, bad dog: Exploring audience uses and attitudes to hyperlocal community news media through the prism of banal pet stories. Anthropological Notebook, 21(3), 39-50.

TV, Internet, gazety, radio: doveryay, no preveryay? [TV, Internet, newspapers, radio: Trust but check?]. (2016, May 4). WCIOM. https://wciom.ru/analyticalreviews/analiticheskii-obzor/tv-internet-gazetyradio-doveryaj-no-proveryaj

Usher, N. (2019). Putting "place" in the center of journalism research: A way forward to understand challenges to trust and knowledge in news. Journalism \& Mass Communication Monographs, 21(2), 84-146. https://doi.org/10.1177/1522637919848362

Weibull, L., Wadbring, I., \& Ohlsson, J. (2018). Det svenska medielandskapet: Traditionella och sociala medier i samspel och konkurrens [The Swedish media landscape: Traditional and social media in interplay and competition]. Liber.

Wenzel, A. (2019). Public media and marginalized publics: Online and offline engagement strategies and local storytelling networks. Digital Journalism, 7(1), 146-163. https://doi.org/10.1080/21670811. 2017.1398594

Willnat, L., Weaver, D. H., \& Wilhoit, G. C. (2019). The American journalist in the digital age: How journalists and the public think about journalism in the United States. Journalism Studies, 20(3), 423-441.

\section{About the Authors}

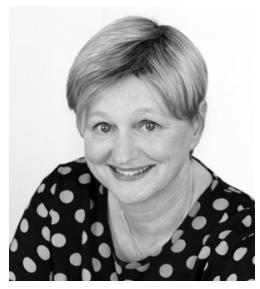

Jaana Hujanen (PhD) is a Professor of Journalism at the University of Helsinki, Swedish School of Social Science, Finland. She has examined and published widely on the ideals and practices of journalism, participatory news media, and uses and perceptions of news and journalism. Her recent research focuses on new forms of local media and communications as well as journalism ethics. Her work has been published, among others, in New Media and Society, Journalism, and Journalism Studies.

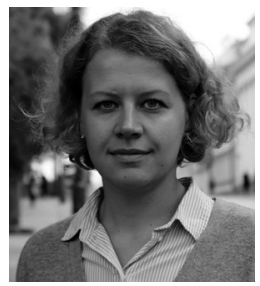

Olga Dovbysh is a Postdoctoral Researcher at the Aleksanteri Institute, University of Helsinki and Coordinator of the Russian Media Lab Network initiative. In her previous research, she examined hyperlocal media in Russia, their social meanings, technological challenges, and economic constraints. From January 2020, she works in the project "Sustainable journalism for the algorithmic future," which studies challenges of algorithmic journalism in Russia and beyond. Her recent works have been published in, for example, Journalism, Social Media + Society, and Demokratizatsiya: The Journal of Post-Soviet Democratization. 


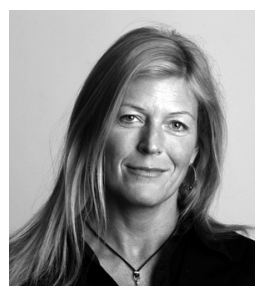

Lottie Jangdal, a Journalist by trade, is a Lecturer at the Journalism Program at Mid Sweden University as of 10 years. Parallel to her teaching, she is a PhD Student at the department of Media and Communication Science with an area of research within local media and democracy. Her work has been published in peer-reviewed journals such as Nordicom Review, Journalism Practice, Observatorio and Problemi dell'informazione. This article will be the fifth and final part of her compilation thesis.

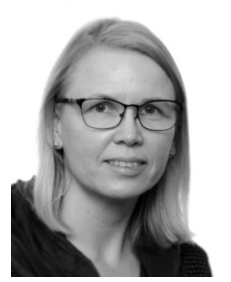

Katja Lehtisaari is Senior Lecturer in Journalism at the Faculty of Information Technology and Communication Sciences at Tampere University, Finland and Adjunct Professor (title of Docent) in Media and Communication Studies at University of Helsinki, Finland. Her research topics include media business and media policy studies, changing media structures and journalism, with international and comparative orientation. Her publications include a wide range of chapters in edited books and articles in peer-reviewed journals like Digital Journalism and Journal of Media Business Studies. 